Revue bibliographique pour le domaine irano-aryen

\title{
James A. Neely. "Parthian and Sasanian settlement patters on the Deh Luran Plain, Khuzistan Province, Southwestern Iran"
}

\section{Rémy Boucharlat}

\author{
(2) OpenEdition \\ Journals \\ Édition électronique \\ URL : http://journals.openedition.org/abstractairanica/47086 \\ DOI : 10.4000/abstractairanica.47086 \\ ISBN : 1961-960X \\ ISSN : 1961-960X \\ Éditeur : \\ CNRS (UMR 7528 Mondes iraniens et indiens), Éditions de l'IFRI
}

\section{Référence électronique}

Rémy Boucharlat, « James A. Neely. "Parthian and Sasanian settlement patters on the Deh Luran Plain, Khuzistan Province, Southwestern Iran" », Abstracta Iranica [En ligne], Volume 37-38-39 | 2018 document 73 , mis en ligne le 30 décembre 2018, consulté le 26 septembre 2020. URL : http:// journals.openedition.org/abstractairanica/47086 ; DOI : https://doi.org/10.4000/abstractairanica. 47086

Ce document a été généré automatiquement le 26 septembre 2020.

Tous droits réservés 


\title{
James A. Neely. "Parthian and Sasanian settlement patters on the Deh Luran Plain, Khuzistan Province, Southwestern Iran"
}

\author{
Rémy Boucharlat
}

\section{RÉFÉRENCE}

James A. Neely. "Parthian and Sasanian settlement patters on the Deh Luran Plain, Khuzistan Province, Southwestern Iran", IA 51, 2016, pp. 235-300.

1 L'A. fut un membre actif du programme nord-américain novateur dans les années 1960 de prospections et sondages dans la région du Deh Luran, dans le Khuzestan près de la frontière irakienne. Les données furent recueillies à partir de 1963, mais surtout en 1968-69. Deux volumes ont paru sur les sites du Néolithique à l'époque achéménide (Hole, Flannery, Neely, 1969, Prehistory and Human ecology of the Deh Luran Plain, et Wright \& Neely, 2010, Elamite and Achaemenid Settlement on the Deh Luran Plain (cf. AI $32-33, n^{\circ} 131$ sous ce titre). L'occupation parthe et sassanide, cette dernière période associée au début de l'Islam dont elle ne peut être facilement distinguée, est la plus importante (263 sites sur 330) toutes périodes confondues. L'A. ne peut aller vers plus de précision dans la chronologie, avec raison, car les datations sont largement fondées sur une chrono-typologie de la céramique contestée depuis longtemps (R.J. Wenke, 1975, dans Mesopotamia X-XI, 1975-1976). Quelques tessons datés par OSL et des monnaies fournissent cependant des éléments de datation.

2 En spécialiste de l'irrigation, l'A. distingue les terres de piedmont irriguées par canaux ou qanāts, terme à entendre ici plus généralement comme des dérivations de cours d'eau, souterraines ou non, par percolation, et les terres de plaine en agriculture sèche, mais bénéficiant, en saison, de l'eau de pluie stockée dans de petits barrages ou dérivée 
vers les cultures. Les terres de piedmonts seraient celles des sédentaires, celles des plaines seraient mises en valeur par des pasteurs transhumant vers les hauteurs au printemps. L'A est tenté de céder à l'extrapolation un peu simpliste par l'économie médiévale et moderne de ces régions de nomadisme (aujourd'hui déclinant). Sa tentative de relier l'évolution interne dans ces périodes historiques avec le mode de gouvernement différent entre l'époque parthe (pouvoir lâche) et l'époque sassanide (empire centralisé) peut difficilement convaincre en l'absence de données textuelles régionales.

\section{AUTEURS}

RÉMY BOUCHARLAT

UMR 5133 CNRS-Université de Lyon 